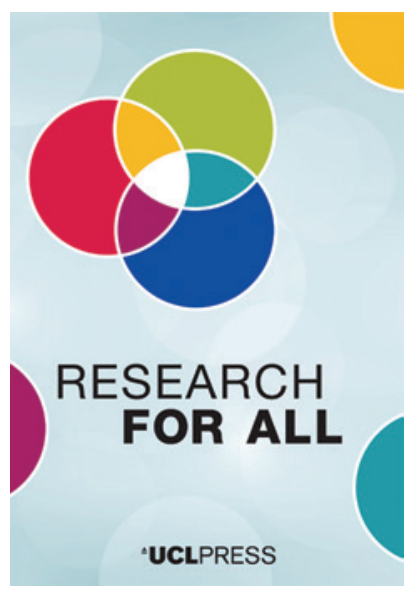

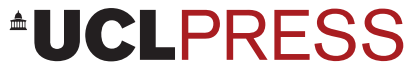

\section{RESEARCH FOR ALL}

The open-access journal for public engagement with research

ISSN 2399-8121 (Online)

Journal homepage:

https://www.uclpress.co.uk/pages/research-for-all

\title{
The Olive Ridley Project (ORP): A successful example of how to engage researchers, conservation practitioners and civil society
}

\author{
Martin Stelfox(D), Mercedes Martin-Cereceda(D, Karim Vahed (D, \\ Jillian Hudgins (D), Stephanie Köhnk (D), Usman Iqbal, Ibrahim Shameel, \\ Joana M. Hancock (iD and Michael Sweet iD
}

\section{How to cite this article}

Stelfox, M., Martin-Cereceda, M., Vahed, K., Hudgins, J., Köhnk, S., Iqbal, U., Shameel, I., Hancock, J.M. and Sweet, M. (2021) 'The Olive Ridley Project (ORP): A successful example of how to engage researchers, conservation practitioners and civil society'. Research for All, 5 (2), 448-73. https://doi.org/10.14324/RFA.05.2.17

Submission date: 30 September 2020

Acceptance date: 27 May 2021

Publication date: 21 September 2021

\section{Peer review}

This article has been peer-reviewed through the journal's standard double-blind peer review, where both the reviewers and authors are anonymized during review.

\section{Copyright}

(c) 2021 Stelfox, Martin-Cereceda, Vahed, Hudgins, Köhnk, labal, Shameel, Hancock and Sweet. This is an open-access article distributed under the terms of the Creative Commons Attribution Licence (CC BY) 4.0 https://creativecommons.org/licenses/by/4.0/, which permits unrestricted use, distribution and reproduction in any medium, provided the original authors and source are credited.

\section{Open access}

Research for All is a peer-reviewed open-access journal. 


\title{
The Olive Ridley Project (ORP): A successful example of how to engage researchers, conservation practitioners and civil society
}

Martin Stelfox ${ }^{1}$ - Olive Ridley Project (ORP), UK; University of Derby, UK Mercedes Martin-Cereceda'* - University of Derby, UK; Complutense University of Madrid, Spain

Karim Vahed - University of Derby, UK Jillian Hudgins - Olive Ridley Project (ORP), Canada Stephanie Köhnk - Olive Ridley Project (ORP), Germany; University of Hamburg, Germany

Usman lqbal - Olive Ridley Project (ORP), Karachi, Pakistan Ibrahim Shameel - Olive Ridley Project (ORP), Maldives

Joana M. Hancock - Olive Ridley Project (ORP), Kenya; ISPA-Instituto Universitário, Lisbon, Portugal

Michael Sweet - Olive Ridley Project (ORP), UK; University of Derby, UK

\begin{abstract}
The Olive Ridley Project (ORP) was set up to protect sea turtles and their habitats. The project was formed in 2013, and it became a registered charity in the UK in 2016. From its inception, ORP took a multidisciplinary approach to achieve its goals. Part of its objectives, and the reason why the charity came to fruition, are related to the issue of olive ridley sea turtle (Lepidochelys olivacea) entanglement in abandoned, lost or discarded fishing gear (also known as 'ghost gear' or 'ghost nets'), and the search for ghost gear and turtle entanglement 'hot spots' throughout the Indian Ocean. The initial ORP research questions were soon challenged by societal interests to develop inclusive educational programmes in local communities and tourist resorts that could raise awareness about the need for conservation of all sea turtle species. In February 2017, ORP opened the first veterinarian-run, fully equipped Marine Turtle Rescue Centre in the Maldives, bringing together the work of researchers, citizen scientists, volunteers, environmentalists, marine biologists and veterinarians. The present work of ORP sits on a strong and scientifically robust collaborative plan. Current ORP research projects range from sea turtle population analyses, spatial ecology, rehabilitation of injured and sick individuals, epibiont parasite analyses, precise turtle identification through photo-ID research, linking ghost gear to responsible fisheries, and analyses of ghost gear drift patterns. The programme enhances community education and outreach by engaging schoolchildren, organizing workshops, promoting sustainable use of ghost gear waste, and training citizen scientists and local fishing communities. The ORP programme encompasses many principles of research engagement, effectively combining scientific knowledge, education and action. This article explores all stages of the process (from research planning and design, to knowledge exchange and inter- and trans-disciplinary impact assessments), describing the active engagement originated by the ORP
\end{abstract}


initiative. A reflective insight into the learning, enrichment and challenges of engaging researchers and community actors is also included, considering the current social and scientific framework.

Keywords: sea turtle conservation, citizen science, community-based research, local fishing community, circular economy

\section{Key messages}

- Charitable status allows an organization a dual role as researcher and community stakeholder, to align academic and community priorities, and to establish long-term collaborative relationships.

- Reaping economic benefits from environmental research and conservation through designing, producing and selling fashion items made from abandoned materials - the circular economy - has made it more sustainable.

- Incentivizing citizen scientists by providing immediate feedback and real-time analyses of the data they submit via the website has led to more data and more accurate research.

\section{Introduction}

In recent years, the argument that research should be 'with and for society' has moved into the limelight of research agendas worldwide (Krogh and Nielsen, 2017; Nielsen, 2016; Owen et al., 2012). The European Union (EU) Research and Innovation Programme Horizon 2020 was launched with an emphasis on tackling a list of 'Grand Challenges', also called 'Societal Changes' (European Commission, 2020), and aimed to address research within a cooperative international context.

There are many challenges in managing a successful engaged research process, and several authors have addressed these challenges. For example, Krogh and Nielsen (2017) have developed a conceptual scheme to reflect two types of research: research without society, and research with society (that is, engaged research). These authors go further, and make an additional distinction between engaged research for society (action research) and engaged research about society (interactive research). The same study (Krogh and Nielsen, 2017) also advises researchers to pursue three key goals. First, initially set up working groups (or any other permanent structures of interaction) which allow for periodic discussions of the research with engaged partners. Second, apply methods that warrant the inclusion of a variety of perspectives on the research process. Third, establish a clear division of roles and responsibilities among the parties engaged in the research.

One might argue that the research engagement principle that is most inclusive of society is probably participatory research, or participant action research. In this context, the aim is to facilitate those who would not normally look upon themselves as researchers to adopt that role, and to undertake research into issues that matter to them by gathering and assessing data. Participatory research combines research, education and action. As such, it differs from 'traditional' social research in that the communities of interest are not passive observers in the research and sources of data; they are involved in the research process through collaborative inquiries and possibly contributing to decision making, project planning, research design, data collection/ analysis, and generation and dissemination of knowledge that can be used to address practical concerns (Southby, 2017). 
In the marine research field specifically, several comprehensive arguments have been posited to connect research and society. For example, Hind et al. (2015) suggest a list of recommendations for good practices to engage (effectively and collaboratively) international marine research activities in small island states. Based on their own experiences, the authors propose that when research priorities are aligned, longterm relationships can be established, local capacity is then enhanced, and research products are well communicated. This results in a greater likelihood of success for all involved, ultimately resulting in improved marine resource management skills.

For conservation activities and science, an 'all-inclusive' approach is also essential for success and to ensure longevity. It is therefore important to conceive, conduct and implement research initiatives that lead to strong conservation outcomes and do not cause negative impacts on communities and/or compromise future research efforts. Recently, Chin et al. (2019) have suggested that the engagement areas on which to focus are careful and considered planning and preparation, and effective collaboration and reciprocity, arguing that both provide appropriate conduct and protocol to help ensure that local actors and communities remain engaged. By nurturing these areas, all parties involved can receive genuine benefits, such as capacity building for local participants, and leadership and community practice for the researchers. These initiatives can likewise bring about robust and long-lasting conservation benefits by facilitating local communities to undertake further conservation projects independently (Hind et al., 2015).

As well as the practice of 'parachute science' (when wealthy Western researchers 'drop down' from an ivory tower to conduct work in developing countries without engaging with the local communities or regional/national research teams), a factor that has hampered the development of engaged research in marine science and conservation is the generally low level of diversity among scientists and practitioners in these research areas. Some researchers have proposed actions that can be taken to increase the diversity of the research workforce in areas such as marine conservation, for example, the establishment of an online Marine Diversity Network (Smith et al., 2017). Others have highlighted the concept of 'blue growth' or 'one health', both of which propose that for effective ocean management to be undertaken, we need to recognize that diverse ocean uses and marine ecosystem services are interconnected and therefore should be managed jointly (Burgess et al., 2018; Cziesielski et al., 2021; Sweet et al., 2021). Indeed, several guidelines for success in this field have been discussed, of which effective stakeholder engagement involving co-management and citizen science, as well as the evaluation of impact and 'learn as you go', stand out as important tools for managing blue growth.

Other studies argue for the importance of marine social science in research and practice, in order to account for the human dimension of marine management and policy, and to understand the degradation of marine and coastal ecosystems, and the relationship between society and the sea (for example, McKinley et al., 2020). In this context, the need to improve capacity for marine social science research on a global scale has been highlighted, along with the importance of nurturing a marine social science research community, and the role of networks such as the Marine Social Sciences Network in data and knowledge exchange and producing evidence. Indeed, it is unarguable that people and their anthropogenic activities are one of the most pressing challenges that the seas are facing (Pascual et al., 2017). That said, the conversation around marine and coastal management is now showing a growing recognition of the potentially positive role that individuals and communities may play, specifically, through environmental citizenship or citizen science involvement (Kelly et al., 2020). 


\section{Rationale}

Despite numerous efforts to integrate marine research and conservation within civil society, there is still a lack of practical research initiatives that target many of the societal problems of current interest in marine science. In the interim in-depth assessment of the Horizon 2020 programme (European Commission, 2018: 52), one of the three key areas identified for improvement was outreach to civil society, highlighting the need to 'better communicate the results and impacts of R\&I [research and innovation] for society, and involve users and citizens more in the agenda-setting \& implementation (co-creation)'.

In July 2020, we performed a literature review using Web of Science (https:// login.webofknowledge.com/), and retrieved all manuscripts published in the last 15 years containing in their title, keywords or abstract any combination of the terms 'nongovernmental organization' or 'NGO' with one of the following terms: 'university', 'education', 'marine conservation', 'marine research' or 'community development'. The term 'charity' was also tried, but this rendered only a couple of entries; therefore, we decided to use 'NGO' in our search.

Our review highlighted that the work of NGOs is largely associated with education, or involving universities, but that there is a lack of NGOs working on marine research/conservation and community development (Figure 1).

Moreover, the manuscripts retrieved that contained our paired searches covered numerous thematic categories (Web of Science disciplines), with most (more than one hundred disciplines) being exemplified in the 'education and NGO' and 'university and NGO' searches. Specifically, for these two searches, the thematic category Educational Research (57 per cent and 54 per cent respectively) was the most represented. The

Figure 1: Number of manuscripts from the last 15 years (Web of Science, accessed 20 July 2020, https://login.webofknowledge.com/) containing in the title, keywords and/or abstract each of the paired search terms shown in the figure legend (credit: authors)

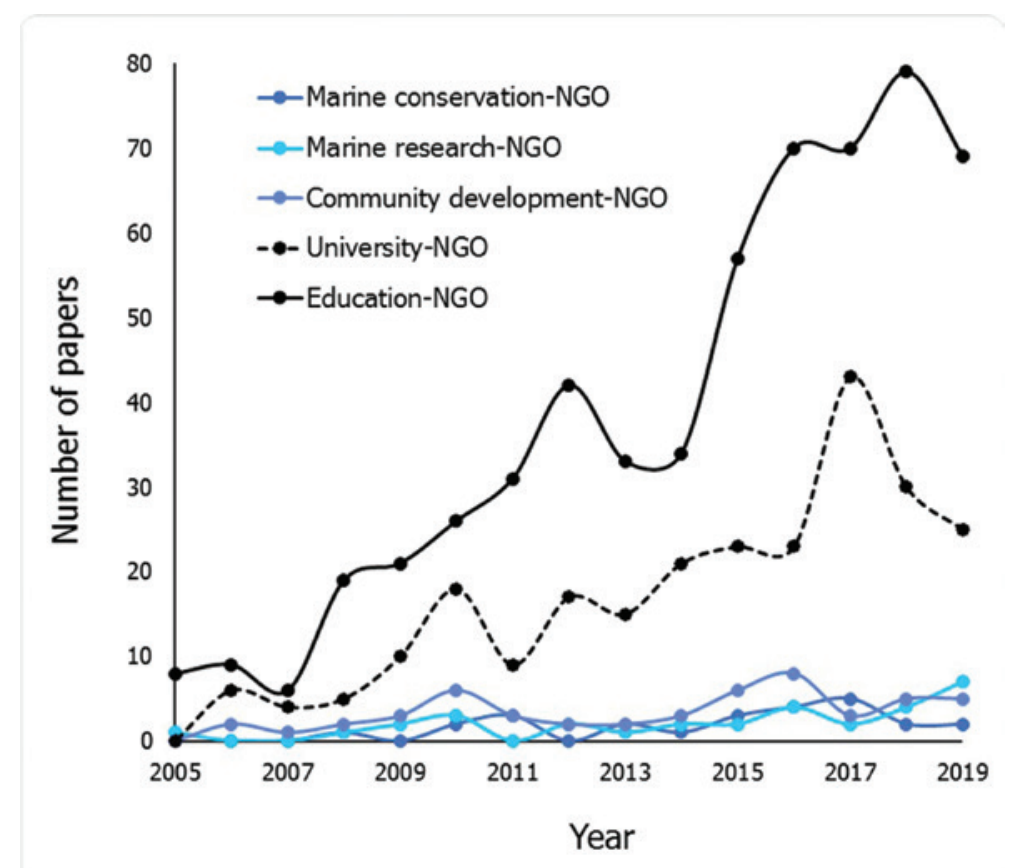


thematic categories covered by the searches 'community development and NGO', 'marine research and NGO' and 'marine conservation and NGO' were much less diverse (42, 24 and 17 categories respectively). The most represented thematic category for these searches was Environmental Studies (41 per cent, 36 per cent and 36 per cent for each area respectively; for more details, see Figure 1S in Supplementary Data S1, https://oliveridleyproject.org/stelfox-et-al-2021-supplementary-data). Taken together, these analyses suggest that the areas of community development, marine research and marine conservation still need to unfold in terms of research involving NGOs and their educational and societal implications. The Olive Ridley Project (ORP) team has been developing these areas in its research engagement since 2013. Here, we share ORP's experience exploring the benefits and challenges of establishing partnerships with local communities, and public and private organizations, with the aim to pave the way for an inclusive science paradigm in the marine disciplines.

\section{The Olive Ridley Project framework}

In the Agenda of the United Nations (UN) for Sustainable Development Goals (SDGs), the current framework that relates to the Grand Challenges identified by the EU in Horizon 2020 (United Nations, 2020), several of the 17 SDGs are explicitly focused on the increase of health financing, and the recruitment, development, training and retention of the health workforce in the most vulnerable countries - for example, African countries, small island states, low-income countries and/or countries in situations of conflict and post-conflict. The initiatives of ORP are taking place in countries included under these criteria. Initially, ORP started operations in the Maldives, with additional initiatives added in other Indian Ocean nations (Pakistan, Oman and Kenya). The Maldives, the main country of ORP's actions, is identified by the UN as one of 37 Small Island Developing States (SIDS). These states are often discussed in terms of common features: island or archipelagic state; small land mass; remoteness; trade dependence and vulnerability to external supply and demand shocks; limited resource base; and exposure to environmental change (Campling and Rosalie, 2006; UNDESA, 2017). Moreover, SIDS tend to have higher average per capita incomes than landlocked developing countries, yet, at the same time, they are among the middle-income countries with the largest debts in the world. In 2012, 12 of the 20 most indebted states were SIDS (Silver and Campbell, 2018).

The ORP objectives and actions entirely fit within the UN goals SDG 13 (Climate Action), SDG 14 (Life under Water) and SDG 17 (Partnerships). Within their targets, these goals specifically state: 'Take urgent action to combat climate change and its impacts' (SDG 13); 'Prevent and significantly reduce marine pollution of all kinds, in particular from land-based activities, including marine debris and nutrient pollution', 'Sustainably manage and protect marine and coastal ecosystems to avoid significant adverse impacts, including by strengthening their resilience, and take action for their restoration' (SDG 14); and 'Strengthen the means of implementation and revitalize the global partnership for sustainable development' (SDG 17).

To set in context the work that the ORP team is undertaking, and how the organization works systematically to develop a programme of engaged research, we illustrate the project framework (Figure 2). The framework embraces the different stages in the development of a research project with the four focal areas considered by Hind et al. (2015) for fostering effective and co-enriching marine science collaborations in small island (and similar) states: (1) aligning of priorities; (2) building long-term relationships; (3) enhancing local capacity; and (4) sharing research products. 
Figure 2: Framework for the Olive Ridley Project (ORP), including all the action areas tackled by the organization (credit: authors)

\section{ORP Framework}

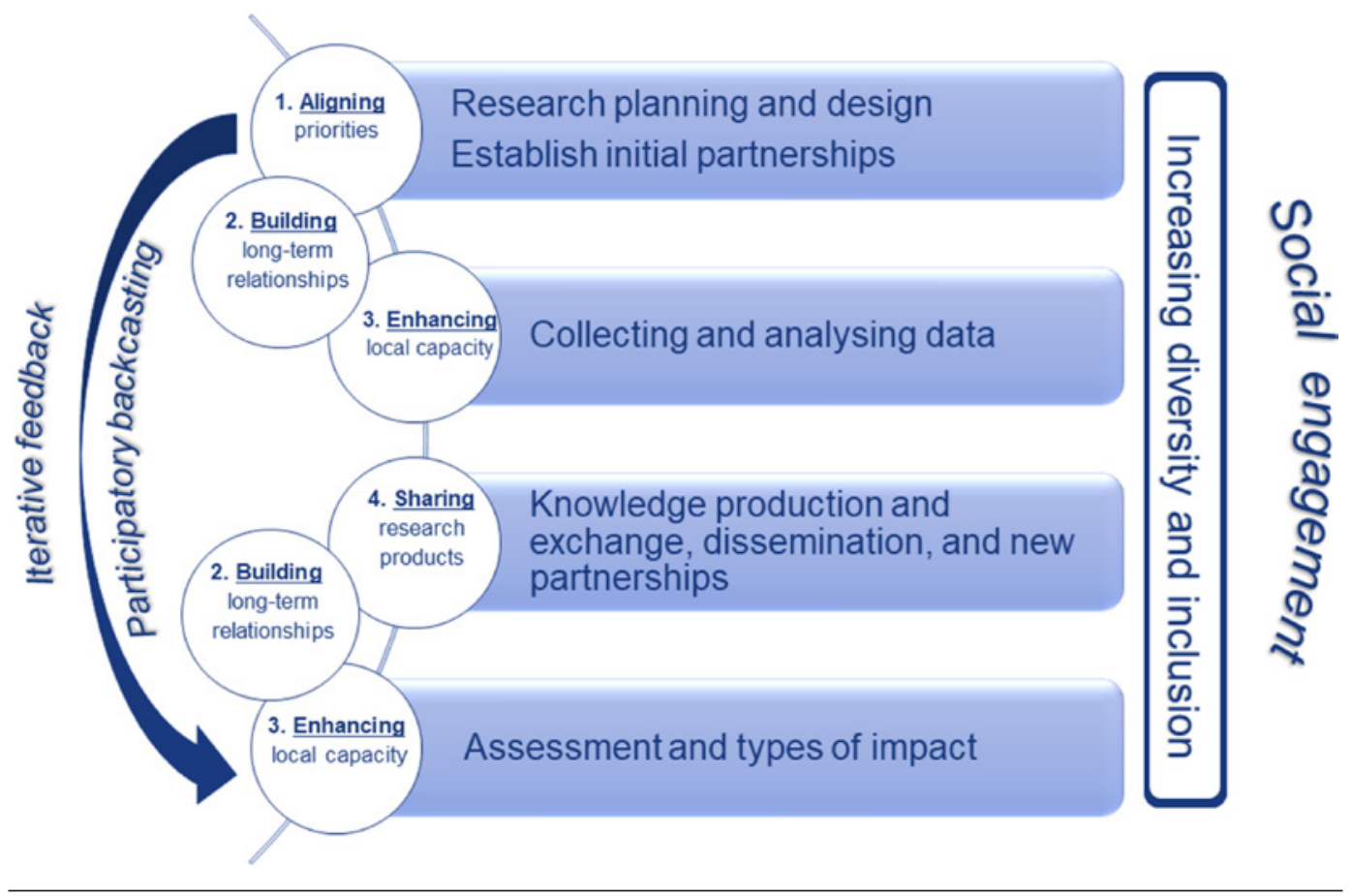

Below, we describe the synergies and the developed channels of inclusive collaboration between researchers and targeted communities along every step of the research project, from inception to impact assessment, following a feedback and iterative loop and adding a 'participatory backcasting' perspective that enriched the process of engagement.

\section{Research planning and design, establish initial partnerships}

The research was originally formulated in dialogue with the community to target a very specific question: 'Where are the ghost nets found in the Maldives coming from, and what is the impact on olive ridley sea turtles?'. This led to the foundation of a charity as a service-user instrument to align priorities and tackle the research tasks. Very early in the process, a consultative group originated through the technical partnership of ORP with the International Union for Conservation of Nature (IUCN), the Marine Research Centre of the Maldives (MRC), and marine biologists and key actors in the marine sector working in the Maldives, as well as the funding of the company Global Blue. This collaboration built up the early development of the data collection on ghost gear that ORP has since implemented and maintained as a research priority.

\section{Collecting and analysing data}

The initial data gathering brought up additional societal challenges and questions of environmental and conservation concern, including: 'What is the global impact of ghost gear entanglement on marine fauna in general?'; 'Why is the olive ridley the most affected turtle species in the Maldives?'; 'What is the ghost net distribution in the Indian Ocean?'; and 'From which fisheries do the ghost nets originate?'. The aim was 
to identify responsible fisheries so that they could be reached to discuss solutions on limiting the loss of nets in the first place. These questions required a formal reorientation of the research planning and design.

One of the key aspects of ORP from the beginning was to ensure the involvement of local researchers, volunteers and tourists at the resorts when and where possible to enhance the local capacity. Therefore, the collection and analysis of field data involved the active participation in the research process of affected and target community groups (citizen scientists), who increased the versatility and applicability of the research findings.

The analysis and interpretation of data were approached collectively through the multidisciplinary experience of ORP members. Furthermore, ORP engaged with additional organizations and activists (such as the Global Ghost Gear Initiative $(G G G I))$ to ensure that the reach of the charity was more international. ORP currently sits on two working groups within GGGl: the Build Evidence Working Group, which guides stakeholders on data standardization of ghost gear worldwide and provides experience in challenging locations; and the Best Practice and Inform Policy Working Group, which informs other stakeholders on the best methods to deal with ghost gear.

As part of UK charity law, ORP prepares and signs a Memorandum of Understanding with every entity with which the organization collaborates. Memoranda of Understanding support collaborations, supplement informal/verbal agreements and contribute to build long-term relationships.

One of the most representative examples is the long-term partnership ORP has established with Coco Collection resorts. This partnership began in 2015, with the help of resident marine biologist Chiara Fumagalli. ORP and Coco set out to build the first veterinarian-led sea turtle rescue centre in the Maldives. This came to fruition in February 2017 with the opening of the Olive Ridley Project Marine Turtle Rescue Centre at Coco Palm Dhuni Kolhu, where turtles of different species are taken care of, and released back into the wild if and when recuperated. Between opening in February 2017 and February 2020, the centre treated 124 patients: 98 olive ridley turtles, 16 hawksbills, 9 greens and 1 loggerhead. Over the past three years, 59 of these turtles have required rehabilitation and have been released successfully back into the wild. The veterinarians have performed over one hundred surgeries, with some turtles requiring multiple procedures.

\section{Knowledge production and exchange, dissemination, and new partnerships}

The expertise and resources of ORP's researchers and community members have been utilized inclusively to translate the research findings into outputs. Besides the production of manuscripts (for a list of peer-reviewed manuscripts, see Supplementary Data S1, https://oliveridleyproject.org/stelfox-et-al-2021-supplementary-data), the aim was also to provide recommendations for policymakers. These have included, for example: reduction in gill-net fishing capacity in the region; improved net disposal facilities in ports; a no-blame gear loss reporting system; improved gear marking; and identifying new technologies to track and trace gear loss rates. The science to policy concept in turn has generated further research questions about the turtles' ecology and natural history (for example, population and community analyses, spatial distribution patterns, epibiont and parasite studies). All of this interactive knowledge opened the door to identify ways to undertake education and capacity-building tasks along the way (for example, shifting community attitudes from exploitation to conservation of turtles and their habitats). The knowledge produced has fed back to 
the research design stage, with new collaborations and challenges to create original and exciting ways to share the research products through long-term partnerships with several resorts in the Maldives, the Maldives Underwater Initiative Partnership (MUI), World Wide Fund for Nature (WWF) Pakistan, the Pakistani government (Sindh Wildlife Department), individual artisans, the Marine Research Centre of the Maldives, and the International Union for Conservation of Nature.

The research generated by ORP is producing knowledge exchange and knowledge translation. ORP has run several initiatives between communities, researchers and academics that have gone beyond the academic outputs of the research, including the following:

- Community workshops, seminars and marine education programmes with students from local schools. Further turtle festivals have been organized. The activities all aim to spread awareness in local communities and tourist resorts about the conservation of sea turtles in the region, and to transfer knowledge to citizen scientists. (For details of quantitative indicators of educational resources, see Supplementary Data S1, https://oliveridleyproject.org/stelfox-et-al-2021supplementary-data.)

- Additional bespoke outputs for the community (for example, posters and leaflets available via the ORP website (https://oliveridleyproject.org/), such as 'Assessing populations of sea turtles in the Maldives using photo-ID', and 'The potential for a citizen science photo-ID program to better protect marine turtles in the Maldives'.

- Production of easy-to-read reports (for example, Atlas of the Maldives: A comprehensive inventory of organisms affected by ghost nets in the Maldives (ORP, n.d.)).

- Development of user products (for example, the establishment of novel data sets on the location and type of fishing nets, and identification of turtles) lodged in an online portal on the ORP website.

All these activities have facilitated building additional long-term relationships to channel the instruments of an effective knowledge translation. One of the most emblematic partnerships established in this stage of the research engagement process has been to team up with the fashion designer Waqar J. Khan, founder of Nasheman (https://nasheman.studio/). Nasheman is an ethical fashion brand which focuses on the preservation of crafts where each garment is handcrafted by artisans in rural communities across Pakistan. Through this partnership, ORP teams in Pakistan are able to convert ghost nets into bracelets, linings for fashionable shirts, donkey harnesses and dog leashes. Most of the work done so far has taken place in Abdul Rehman Goth, an old fishing village in Pakistan.

\section{Assessment and types of impact}

The benefits of ORP's activities have worked at three key levels - individual, community and institutional - reflecting the inter- and trans-disciplinary nature of the engagement through the overlapping of the different types of impact generated by the long-term ORP research programme. These include:

- Economic impact - instrumentalized through: (1) the creation of the Marine Turtle Rescue Centre in the Maldives (in February 2017) and the Sea Turtle Rehabilitation Centre (in October 2019), which have employed marine biologists and veterinarians (for details of the staff directly engaged with ORP since the charity was founded, see Supplementary Data S1, https://oliveridleyproject.org/ 
stelfox-et-al-2021-supplementary-data); and (2) the collaboration with the brand Nasheman and community artisans on the design of products recycling ghost gear, for whom these products can pose a significant addition to household income (for details of quantitative indicators of circular economy, see Supplementary Data S1 and S2, https://oliveridleyproject.org/stelfox-et-al-2021-supplementarydata).

- Environmental impact-ORP has improved the awareness and understanding of the effects of ocean pollution, and the consequences of climate change, and stimulated public debate on the environment through the numerous educational resources created. This has provided a strong keystone to civil and civic societies (through the partners within the Global Ghost Gear Initiative, for example), and channelled exemplar sustainable use of the targeted environmental problem: recycled ghost gear into dog leashes and wrist bands, as mentioned above, and the design and construction of a hut in Pakistan made from 3,600 plastic bottles (rescued from the ocean) and held together with monofilament ghost nets. Incidentally, the hut is now used to house all the ghost gear recovered by the community.

- Policy impact - a commissioned report for the United Nations Environment Programme (UNEP) was produced (Sweet et al., 2019), as well as several technical reports for the Indian Ocean Tuna Commission (IOTC), and practical guides and other 'grey' publications (for example, atlases for all types of ghost nets retrieved in the Maldives, and also for all associated marine organisms found).

- Professional and public services impacts - development of new working practices and training protocols (guidelines published on the ORP website, for example: 'Finding an entangled sea turtle'; 'Sea turtle code of conduct'; 'Ghost net data protocol'; 'How to identify a sea turtle'; and 'e-Turtle school').

- Internationalization impact - ORP originated in the Maldives, but it has since extended to other countries (Oman, Kenya and Pakistan), where ORP teams of researchers and collaborators are educating communities (such as fishers in the area), and working on the collection, recovery and reuse of ghost nets, and/or filling gaps in sea turtle research in the region.

- Capacity building and pedagogic impacts - a good example is where ORP enhanced the local capacity of the artisan women in the fishing village of Abdul Rehman Goth, Pakistan. Dr Seher Mirza, a specialist in constructive textiles and craft community development, taught the women how to design and produce bracelets from ghost gear. These women are now selling the upcycled ghost net bracelets and other colourful accessories they create to obtain an extra income that can be a significant addition for their households. All the proceeds from ORP's ghost net bracelet sales go back to the village of Abdul Rehman Goth: 35 per cent is paid directly to the artisan who created the bracelet; the rest goes into a common fund set up to improve the livelihood of the fishing community. Future plans for this scheme include establishing a basic health clinic in the village to improve health care for the families of Abdul Rehman Goth, as the nearest medical clinic is ten kilometres away. Engagement and learning processes associated with the partnership with the artisans in Pakistan are analysed in the next section of this article.

There are ORP-engaged community students in Maldivian schools through the educational sessions on the threats that ghost nets pose to marine organisms, and/or the public educational outreach internship programmes developed in the rescue centres. Moreover, ORP's founder and CEO, Martin Stelfox, co-authored a children's book (Stelfox et al., 2020). The book strived to ensure accuracy with its 
scientific content focused on turtles and their conservation, along with attractive illustrations to engage and inspire new generations of conservationists to the cause. All profits from the book feed back into ORP's activities.

- Online public engagement impact - the initiatives that the charity has carried out since its foundation have increased the visibility (reach) and significance of the ORP message on turtle conservation. ORP utilizes online media effectively, including: Instagram (www.instagram.com/oliveridleyproject/), Facebook (www. facebook.com/OliveRidleyProject/), YouTube (www.youtube.com/channel/ UCudtQpJpRM7Annifktxk FSg/videos), Twitter (twitter.com/ORP_INDIANOCEAN) and its own website (https://oliveridleyproject.org/). (For details of quantitative and qualitative indicators of online public engagement, see Supplementary Data S1 and Figure 2S, https://oliveridleyproject.org/stelfox-et-al-2021-supplementarydata.)

\section{Analysis of ORP engagement actions: Learning, challenges and failures}

One of the most original characteristics of ORP is that it plays a role on two sides of engaged research collaboration, being sometimes a researcher actor and sometimes also a community/stakeholder actor. NGOs and charities may not always have staff with a strong research background. The existence of basic and technical research skills underlying the ORP team has helped to engage as equal partners and to set realistic, mutually beneficial expectations with both academic researchers and community members. We think that ORP's double role in such collaborations is a very clear example of authentic engaged research, as the 'community' is not a passive receiver in this association, but also an active collaborator across every stage of the research process. This has facilitated the establishments of equal partnerships for all ORP's initiatives.

A key to the success of the ORP team is that it has worked on all the different levels recommended to carry out research engaging (with) society. ORP set the foundations for long-term partnerships, generating with imagination and enthusiasm new ideas, concepts, knowledge and outcomes that can lead the charity to future action and interactive research projects, all the while empowering local capacity and innovative sea turtle research and conservation.

Due to the intrinsic connecting nature of ORP (with both academia and wider society), the actions and research developed have been of interest to a large audience: conservation professionals; academics; citizen scientists; local, national and international communities; consultants; early and senior career researchers (marine biologists, veterinarians and ecologists); policymakers; and school, undergraduate and postgraduate students. Therefore, a versatile range of institutions and organizations are the target of the activities that the ORP team has undertaken since its inception, for example: higher education institutions teaching degrees with a strong component of environmental sciences in their programmes; government and civil society organizations (for example, IUCN) and NGOs (for example, the World Wide Fund for Nature, Ghost Diving, Ocean Conservancy, Blue Marine Foundation); private sector organizations (for example, Blue Ocean Gear, Ocean Outcomes, SeaBOS, and aquariums and zoos); and international governmental organizations (for example, the United Nations Environment Programme and the Pacific Islands Development Forum).

ORP has instrumentalized a versatile number of engagement actions to pursue research, societal action and social transformation, as well as followed a variety of 
interactive and creative ways to overcome the challenges of engagement. Below, we discuss some of the most representative engagement methods applied by ORP, and analyse the engagement and learning processes of successful activities, as well as the challenges and failed attempts through the years.

\section{Community-based research and community-based learning methods}

The academic research process has been placed in real-world contexts exploring issues vital to civic engagement, and cultural and economic society. Communitybased research began with a research topic of mutual importance for the researchers/ academics and the NGO members, and combined the knowledge expertise provided by both players with the main goal of achieving social awareness in the local communities and tourist resorts, and enhancing community capacity through service. Community-based learning was engaged by connecting the academic institutions and the charity with communities, and resulted in the gain of academic credit, as well as the reflection of an issue undertaken with and for the community and society (for example, internships of students in the Marine Turtle Rescue Centre in the Maldives; veterinarians' short-term stays at the Rescue Centre; environmental education of schoolchildren; and the accomplishment of PhD degrees (Stelfox, 2019)).

An important learning outcome that was highlighted when working with local fishing communities was not to assume that communities want help or guidance in any particular project. For example, in ORP's early years, it was assumed that all fishing villages in Pakistan found the issue of ghost gear important and wanted to address the issue as a priority to protect their livelihoods. However, surveys of many villages by ORP uncovered a general mistrust between community members and NGOs, resulting in a lack of cooperation and unwillingness to participate in initial surveys. ORP has since learned to listen to general issues of local communities before expressing interest about specific research/conservation projects when approaching new fishing communities.

\section{Community-university service methods}

Community-university service methods emerged from the engagement between researchers/academics/students from universities and target communities in the Maldives and other locations throughout the Indian Ocean. They are mediated by ORP, and conducted, designed and implemented by both the universities and the community through various research programmes (for example, short-term stays from professionals from overseas universities, and university-required placement interning for students at the Rescue and Rehabilitation Centres).

\section{Participatory research and community-empowerment research methods}

The development of participatory strategies by ORP encouraged members of the target communities to have an important say on the allocation and use of resources. Boat captains, divers and vacationers, among others, were the source of citizenscientists who provided data. ORP also has a large network of marine biologists (based in various resorts throughout the Maldives) who have all contributed by actively recording and removing ghost nets when found. Moreover, community empowerment has been embedded into a circular economy action through designing, producing and selling fashion items from recycled ghost nets. Circular economy, as an asset to accomplish sustainability, is increasingly gaining the 
interest of academia, industry and policymakers (Geissdoerfer et al., 2017). As a condition for sustainability, a circular economy is pivotal in the current context of marine conservation and protection. The recycling of ghost nets, undertaken in collaboration with members of the ORP team, local community artisans and innovative companies and organizations, is a clear example of circular economy coupled with community empowerment. This activity minimizes the use of the resource inputs (old fishing nets) and the creation of waste and pollution, providing a means to help the households of community people.

The combination of different engagement principles is valuable for the development and sharing of skills for existing, as well as new, team members, and the successive ongoing projects supported by different sponsors and funding bodies (Ward et al., 2018). By carefully applying the engaged research techniques discussed above, ORP has conducted the collaborations with the aim of 'co-production' not 'production for', to pursue an equal partnership at as many stages of the research as possible, and to engage with collaborators in their own (physical) spaces. Co-produced research and collaborative methods provide great potential for civil organizations such as ORP to work with universities, community organizations, local community people, private business and so on, and to contribute to underpinning social change (Brown and Ward, 2019).

\section{General reflections on participatory research conducted from an NGO perspective}

We think that to tackle research engagement through the eyes of a charity organization, and not exclusively from an academic perspective, has several advantages. Academics may largely be 'research active', while NGOs perceive impact as a crucial aspect of the research, and may take to the concept of being 'research effective' more easily than academics. Moreover, academic researchers are normally required to focus on academically oriented outputs, such as traditional peer-reviewed publications, books, book chapters and conference papers, while NGOs are typically more interested in commissioned and evaluation reports and policy briefings. These latter forms of publication tend to focus more on the long-term processes and methodologies of any given research findings. The fact that NGOs are not subjected to the stress of producing a high ratio of publishable outcomes in short time frames, as the academics are, means that NGOs can focus more on the long-term impact assessments, and encourages the search for collaborative relationships that will last for long periods of time. This is a decisive advantage when visualizing the global learning engagement in the long term, and the application of engaged research design and techniques.

\section{Reciprocal benefit of citizen science engagement}

ORP has two main citizen science initiatives. The first aims to record ghost nets and turtle entanglement through their ocean habitats, and the second aims to understand sea turtle populations through photo-identification methods. The primary objective of the photo-ID initiative is to take photographs of every sea turtle encountered during dives or rescues, so that individuals can be tracked and populations analysed (see, for example, Dunbar et al., 2014; Hancock et al., 2020; Schofield et al., 2008).

Photo-ID encourages participation from tourists and citizen scientists, who only need to take a clear photograph of a turtle's face and submit this photograph to ORP. The reporting of ghost gear, however, is perceived to be less glamourous than 
snorkelling with turtles, and so presents different problems when trying to maintain a global database of records. There was a lack of data submission, resulting in ORP team members spending significant amounts of time chasing leads and hunting down forgotten data. However, the lack of reporting was overcome by switching the methodological process from a 'reward-less' initiative to one that incentivizes citizen scientists by providing immediate feedback and real-time analyses of the data they are submitting via the ORP website. This reinforces the need for their data, and hopefully encourages a level of consistency over time. Indeed, the data generated in both these examples form the foundations for more detailed scientific investigations carried out by ORP researchers. Engaging in such practices means that there is a marked increase in the volume of data gathered compared with if researchers were left to generate this themselves. This in turn results in a parallel increase of model estimates, and more accurate predictions/projections related to the question being asked (see, for example, Stelfox et al., 2019).

\section{Analysis of inclusivity: Women in ORP research}

Since ORP's inception, the team has been composed of 62 per cent female employees originating from nine different countries. Women and girls represent half of the world's population and, therefore, also half of its potential. However, less than 30 per cent of researchers worldwide are women (UNESCO, 2018). Further, only around 5 per cent of all female students select the natural science fields in higher education (UNESCO, 2017). To conduct a strong and cohesive civic society, women should have a crucial role in research (Rasool, 2017), and, in this regard, ORP is an example of inclusion. The engagement procedure to give visibility to the role of women was articulated online through the blog on the charity's website. Testimonies left as answers to the question 'Why did you choose the science and conservation path?' were gathered and published in the ORP blog (ORP, 2020) to mark the International Day of Women and Girls in Science 2020. Table 1 personifies the amplitude and scope of the women engaged in ORP activities. It is interesting to mention that despite the versatility of academic backgrounds and origins of the female researchers involved with ORP, they all highlight the need of conservation in marine science, a field that traditionally has been most overtaken by campaign and sampling expeditions led by men.

\section{Approach to enhance capacity building in local and non-local community actors}

A variety of staff, volunteers and community actors were approached by email with a question: 'What are your opinions on the research and work carried out by ORP, how are/were you involved and how has our research/work affected/changed/benefited your work and lives?' Feedback was received from 13 people from five different countries. In their replies, we identified three main areas of engagement: 'professional accomplishment', 'increasing awareness and shifting people attitudes', and 'local community enhancement' (Figure 3). Interestingly, both local and non-local people were represented in the three types of engagement actions, and no particular engagement action was clearly associated with a particular country or with the condition of the individual being a native of the community or not. It is also interesting to point out that several of the local people who got involved in the ORP team were people who knew each other, and also who had arrived at the charity through other charities working in the area. This demonstrates the interactive and healthy networking that exists among 


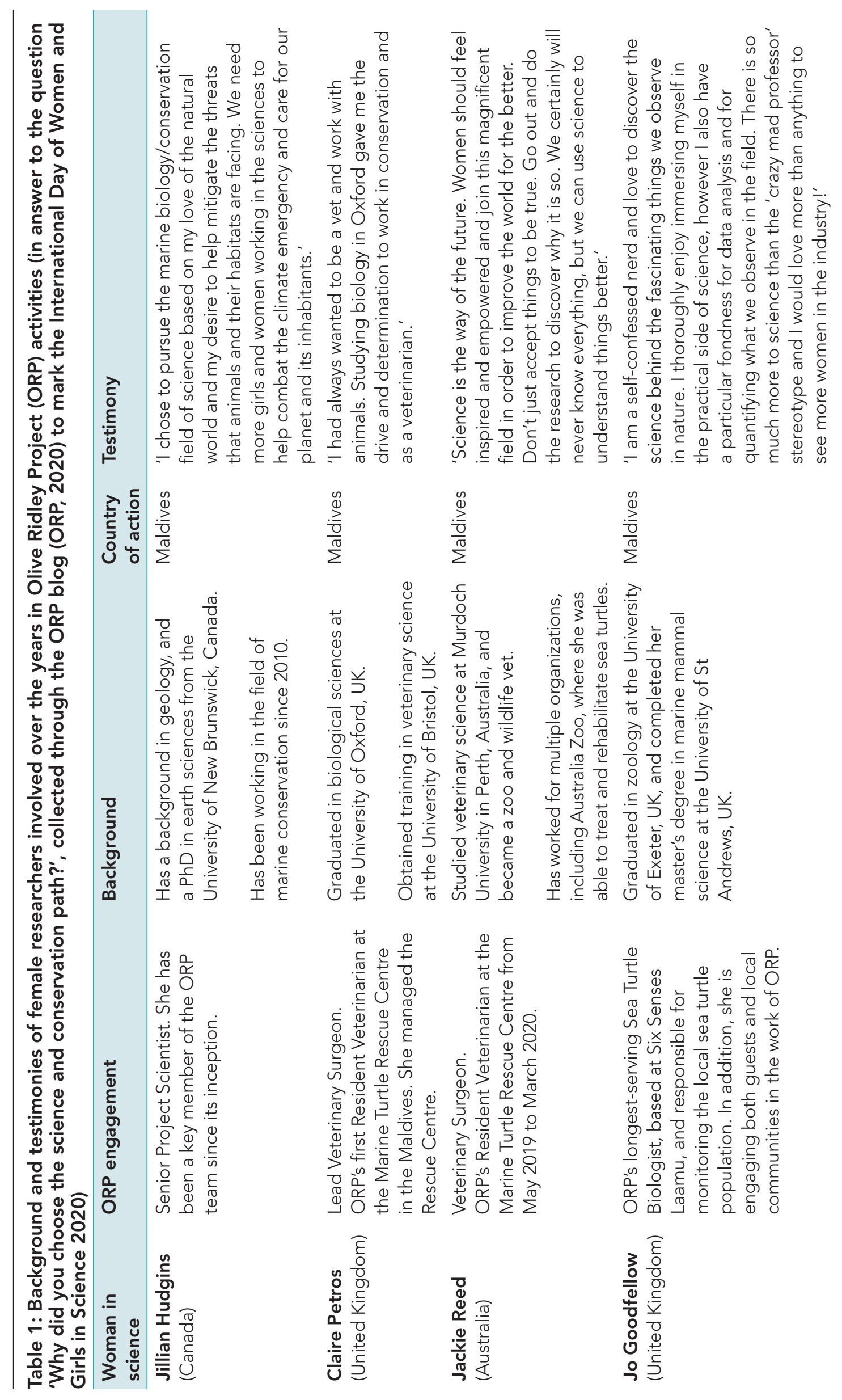









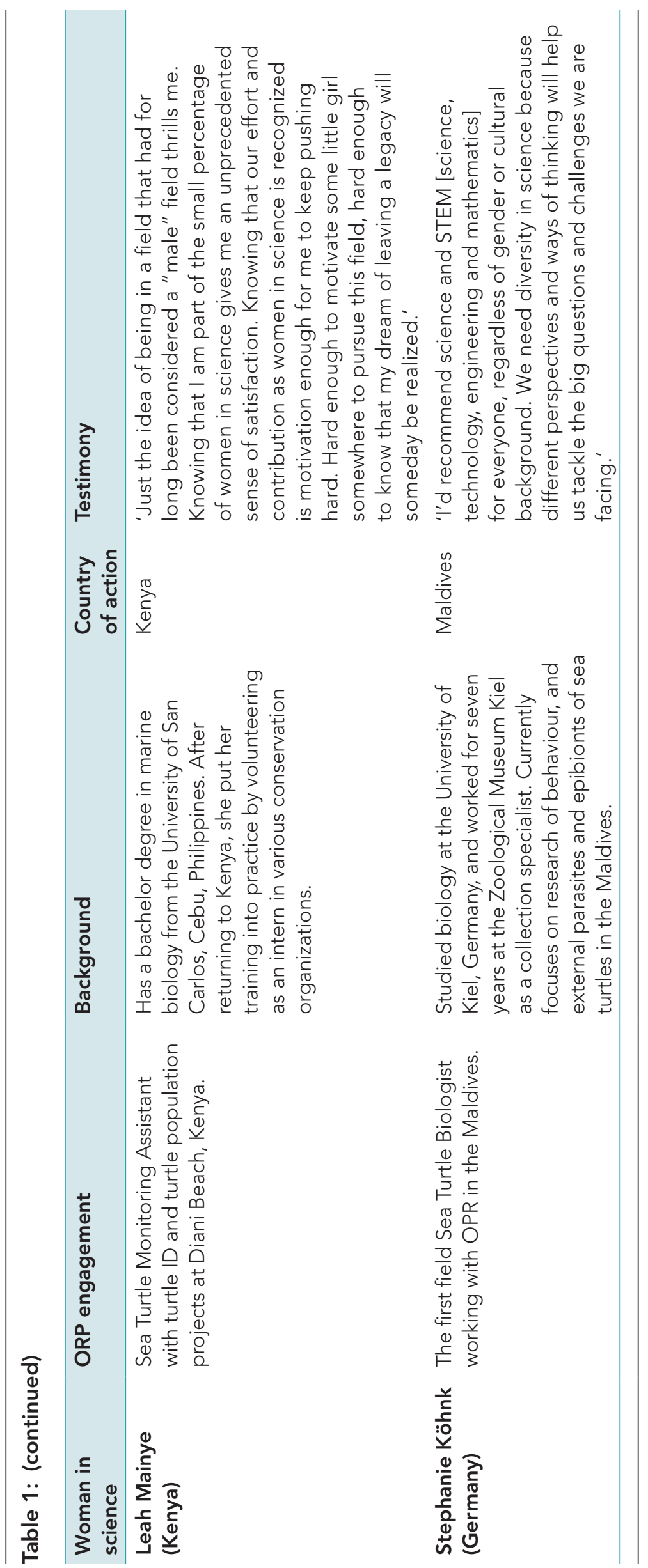


Figure 3: A representation of testimonies provided by the ORP team and community members involved in charity activities (credit: authors)

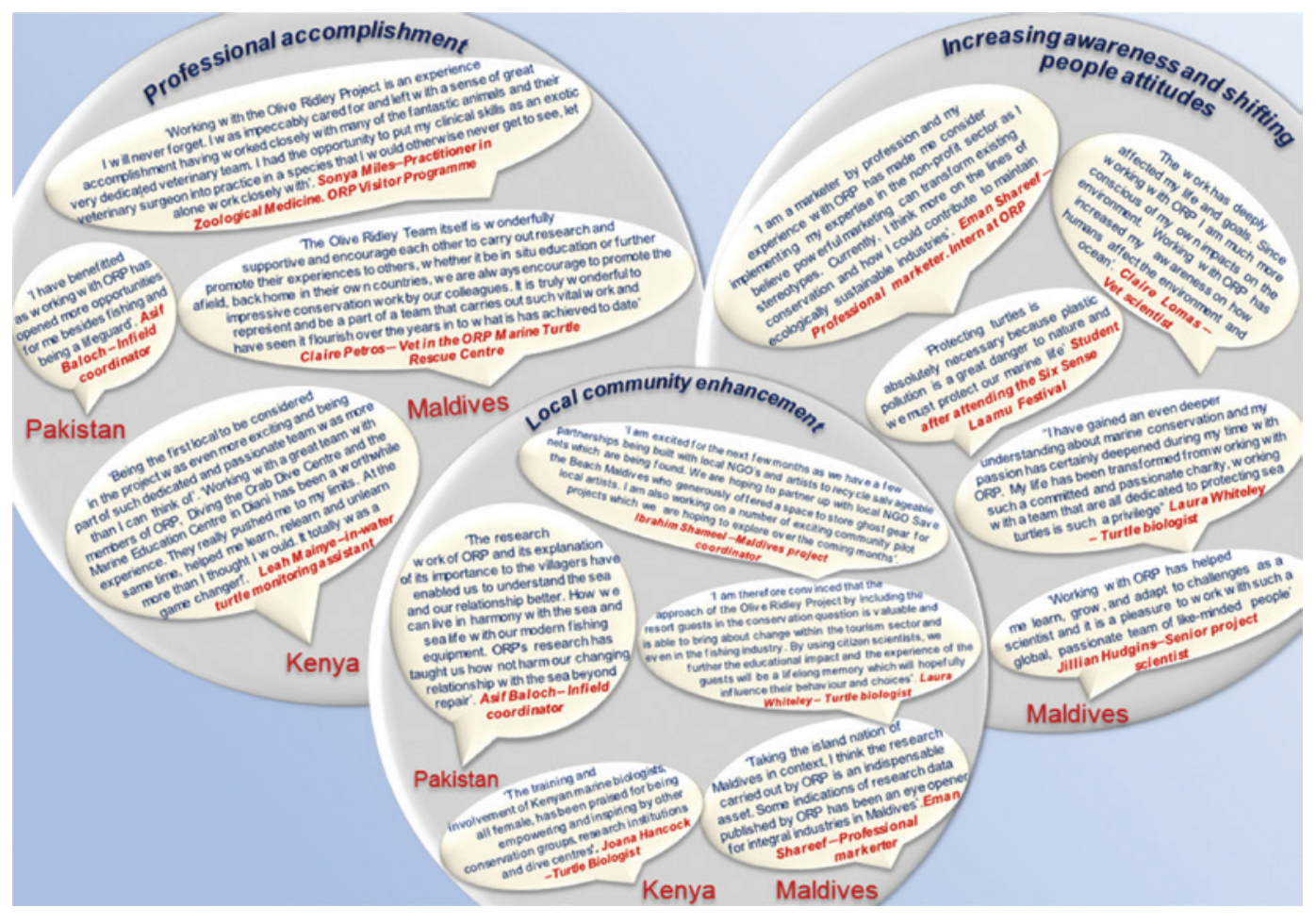

charities focusing on conservation aims. (A complete description of the testimonies provided in Figure 3 is included in Supplementary Data S1, https://oliveridleyproject. org/stelfox-et-al-2021-supplementary-data.)

\section{Perseverance within community settings}

ORP's first visit to Pakistan was in 2015 to conduct fisher surveys on the issue of ghost gear and ghost fishing in Karachi. In total, seven artisanal fishing communities were surveyed, all in close proximity to sea turtle nesting beaches. Directly, the surveys helped to uncover spatial hot spots of ghost net production, and to identify communities where collaboration on the issue was possible. Indirectly, the surveys were able to highlight individuals within each community who showed particular interest in the problem of marine pollution in general. ORP identified one fisher, Asif Baloch, from the Abdul Rehman Goth community as a particular individual who demonstrated a deep understanding and concern for marine pollution, and who openly requested ORP's expertise and guidance on the problem of abandoned, lost and discarded fishing gear in his region.

This was when ORP first began working with the Abdul Rehman Goth fishing community, but it started off extremely slowly. It was one thing to have a dedicated and passionate individual help to educate and inform the community on the issue, but trying to convert the majority of the community (over two thousand fishers) to believe in the project was a major hurdle. Simply, ORP wanted to reduce the amount of ghost gear in the area, and therefore minimize the threat to nesting and foraging sea turtles. To overcome this 'hurdle', ORP first started with community engagement, with a series of workshops and seminars led by ORP's research team consisting of the CEO and founder, Dr Martin Stelfox; ORP Pakistan's project coordinator and co-founder, Absar 
Khan; and fisher, Asif Baloch. These informal gatherings gave the team a chance to introduce ORP to the wider community, and to provide a platform for individuals within the community to voice their concerns and issues in general. ORP simply acted as a sounding board, and made a conscious effort to only act as an intermediate body and to listen to the issues raised. Additionally, ORP's CEO quickly realized that a temporary switch from a vegan diet to one that included fish was required to blend in with the community and to ensure that declining offerings of seafood did not become a cause for suspicion among the community.

ORP quickly became aware that ghost gear and ghost fishing was an extremely low priority within the community, and that basic health care, education and sanitation were far more pressing matters. ORP also identified that the majority of the community were extremely sceptical, and initially ORP was only given access to speak with the men, despite women playing a pivotal role in such fishing communities. ORP continued weekly informal gatherings for around 12 months, each time adding a little more information about ghost gear and ghost fishing, but largely allowing the discussions to flow organically in any direction. ORP's weekly persistence within the community resulted in a build-up of trust within the wider community as suspicion over ORP's intentions dissipated. From these foundations, ORP was able to arrange formal meetings with the community elders, who are respected leaders within the Abdul Rehman Goth community. This allowed ORP to focus the discussion on the issue of ghost gear specifically, and the impact it was having on fisher livelihoods, and to present possible solutions. After several successful meetings with the community elders, the team became widely accepted within the community, and this was reinforced by the community donating land to ORP that would allow for the storage of end-of-life fishing gear.

Over the next year, ORP began organizing more focused educational workshops, specifically targeting the impact of ghost fishing on fisher livelihoods. This was a unique way for ORP to showcase to the community images and videos that capture the destructive power of ghost gear. Asif Baloch became the focal point for all marine pollution or marine animal entanglement events in the village, and his educational workshops (which were developed by ORP) extended deep within the community. This resulted in a dedicated clean-up crew that would recover ghost gear from beaches, and dispose of end-of-life gear. The community, along with the ORP in-field team, developed a hut made from plastic bottles as a safe and secure location to store ghost gear and/or end-of-life fishing gear. Some of the recovered fishing gear was sold to local recycling businesses, and this eventually made a small income for the community. The total amount raised through the recycling programme was enough for the community to fix the village shelter, which firmly cemented ORP's positive intentions with the community, and monetized waste in the region for the first time.

Towards the end of the second year, ORP made connections with local artists to develop innovative products out of ghost gear, with the aim of selling them locally to generate an alternative income extending beyond working with net recyclers. The monetization of ghost gear was well received by the community, which resulted in the Abdul Rehman Goth fishers allowing ORP access to female family members, meaning that the project could develop further. This led to the creation of dog leashes from ghost gear (https://oliveridleyproject.org/shop/ghost-gear-collection/ghost-leash), which now provides a stable and alternative income for the Abdul Rehman Goth community. 
To summarize, through ORP's persistence and perseverance within the community, ORP has been able to achieve its aim to reduce ghost gear and subsequent entanglements in the region, and to develop a sustainable circular economy project that benefits the local environment and improves fisher livelihoods.

\section{Communication challenges and solutions}

One of the greatest challenges faced by ORP is to motivate and ensure that ORP staff and volunteers remain connected despite language, cultural and time barriers. Currently, ORP operates in the Maldives, Pakistan, Oman and Kenya, and works with several different languages, including Dhivehi, English, Balochi, Urdu and Arabic. Often, team members are working in isolation without a network to guide and manage. Although it is important for individual team members to be self-sufficient and able to work independently, the team requested a platform that provided a community where issues and questions could be resolved quickly without waiting for email replies. To address this request, ORP utilized WhatsApp to enable individual team members to communicate in real time and stay connected. More importantly, it was noted that an increase in motivation and morale occurred after utilizing this technology, with some members reporting that they now felt part of a community with a real-time support network to help answer any ORP-related questions. Other more targeted groups using the same media (such as ORP Pakistan) continue to be extremely active. This platform communicates in English and Urdu, but allows both native speakers and non-native speakers to be connected through image upload of net recoveries and animal rescue videos. Words of affirmation and emojis from both native and non-native speakers are positive morale boosts for non-English-speaking fishers who are in the field recovering gear and making products.

In other instances, ORP set up technical WhatsApp groups, and the project in Kenya is a good example of this. Through this group, ORP is now able to communicate directly with rehabilitation efforts in Kenya by Local Ocean Conservation (LOC), and to provide case-by-case guidance for best practice in sea turtle care by the ORP veterinary team. Further communications about ghost gear recoveries and general sea turtle rehabilitation in Oman are largely possible through the communication on WhatsApp groups between the ORP team and key government stakeholders. Communication between all team members is therefore critical, particularly for projects that require independent work environments. ORP also organizes fortnightly video calls when the entire team discuss each project they are working on independently and request additional help if needed. The calls attract all team members, including the CEO, trustees, biologists and project managers, and they provide an additional communication tool to keep on track with charitable objectives and maintain positive morale within the team.

\section{ORP management: Challenges and limitations}

The Olive Ridley Project went from a small one-person activity to a team of over twenty scientists and conservationists in a relatively short space of time. This section reflects on some of the challenges during the early development of ORP, and the challenges faced today as the team grows larger and explores limitations that are yet to be resolved.

ORP was originally set up to address one issue: sea turtle entanglements in the Maldives. Essentially, the ORP founder wanted to understand where entangled olive ridley sea turtles were coming from, and to identify responsible fisheries. Although 
simple in definition, this is technically an extremely challenging issue that requires collaboration between various individuals, organizations, universities, governments and NGOs.

Shortly after the inception of ORP, several interested stakeholders wanted to partner with ORP to help with the issue. This involved hiring more people with various backgrounds and experiences. It quickly became apparent that ORP was becoming well known in the sea turtle community, but it was also wasting a valuable knowledge base from incoming scientists and conservationists. As a result, ORP decided to broaden its scope within the sea turtle conservation space not only to look at the threat of ghost gear, but also to develop new projects that would benefit sea turtle research and conservation. It then became the mission of ORP to protect sea turtles and their habitats through rescue and rehabilitation, education, outreach and research. With new research and conservation projects being taken on board - such as assessment of the current sea turtle populations, genetics analysis of turtles caught in nets and local/ regional nesting populations, tagging of entangled turtles, parasite identification, nest monitoring, foraging ecology, and ghost gear research - the team grew larger, and covered many disciplines within the sea turtle conservation space. The growing team brought with it new challenges that could never have been anticipated early on. Managing so many projects across many disciplines could no longer be handled by the founder alone, and therefore staff structuring was required that would allow ORP to achieve its objectives to protect sea turtles and their habitats. In response, two senior management positions were developed: the Senior Project Scientist, tasked with overseeing all research conducted within ORP; and the Lead Veterinarian, responsible for all rehabilitation-related activities and research. Both senior staff report directly to the CEO/founder, who reports to the trustees of the charity.

After senior-level management, ORP developed project managers who oversee regional conservation projects or lead a small team of researchers and/or conservationists. The project managers report to the senior managers, and provide unique in-country knowledge about which senior team management may not be aware. Project managers typically oversee in-field staff, who are the ones on the ground conducting the research or conservation activity, including scientists, fishers and divers. This hierarchical structure developed within ORP proved an effective way to manage many projects simultaneously, and to maintain accountability for each project objective. By developing the hierarchical structure at ORP, the CEO/founder is able to focus on developing new partnerships and strategies that allow for the longterm sustainability of ORP, and allow the time to develop business strategies that keep the charity focused on its objectives and true to its mission to protect sea turtles and their habitats.

However, there are limitations with the hierarchical structure of the ORP team. First, the structure is intrinsically linked to funding. Without funding, key team members are unable to commit time to manage and oversee research and conservation projects. This reliance on funding is often a major restriction that hinders ORP expansion into additional conservation or research gaps. Second, the team structure in its current form does not allow much room for career advancement for in-field staff. Senior project team positions are typically occupied by long-standing staff members with years of experience working with sea turtles and with ORP, and therefore little room exists for senior positions to become available. Additionally, in-field staff have very few options to expand their career, given the lack of non-senior structuring. However, ORP is exploring options to increase funding (see the next section) that would allow for additional positions, relevant to ORP's mission, to become available at all levels, dependent on individual skill sets. 


\section{Financial dependence in the tourism sector: Pros and cons}

The COVID-19 pandemic has been a challenging time for many small charities and NGOs around the world, and ORP has been no exception. As a sea turtle charity working predominantly in the Indian Ocean, ORP relies on funds raised through commercial partnerships, grants and public donations to continue its rescue and rehabilitation, education and outreach, and scientific research efforts. The major revenue streams for ORP come from the tourism sector through local resorts, and through its volunteering programme. However, when the World Health Organization declared a global pandemic in the first quarter of 2020, many of ORP's resort partners were forced to temporarily close due to travel restrictions, and ORP's volunteer programme was put on hold between March 2020 and February 2021.

Without volunteers and resort partners financially supporting ORP, many in-field staff returned home, leaving only a skeleton staff at the Marine Turtle Rescue Centre (which still had turtle patients), and mostly staff volunteering their time to research and education. ORP's reliance on tourism meant that the pandemic hit hard financially, resulting in remaining funds being used to cover most of 2020. Moreover, funding opportunities are limited within the Indian Ocean region, which has led to the majority of funding being sourced from outside the region where ORP works. This has further highlighted the potential need to expand the project outside the Indian Ocean region to access new funding opportunities and to expand the reach of ORP in the hope of increasing donations. Replicating existing projects already in progress in the Indian Ocean to other regions is a cost-effective way to conduct research in these new locations while simultaneously filling existing data gaps in these areas. Moreover, the experience and resources gained by ORP over the years could be used as a model for other local NGOs starting in different regions. Luckily, 2020 was also a good year for donations outside tourism through ORP's sea turtle adoption programme, which in itself highlights the urgent need for ORP to raise funds outside tourism to ensure long-term sustainability. The learning outcome from the pandemic was to ensure that income streams are diversified within the charity to ensure long-term sustainability. A focus of ORP coming out of the pandemic is to look towards commercial sponsors that are not tied to tourism, and to continue to develop reserve funds to cover for unanticipated events.

Table 2 provides a summary of the immediate and foreseen challenges as a direct result of the pandemic, and the methods implemented to mitigate its impact.

\section{Future perspectives}

The need for creating networks that connect the various actors for the development and implementation of effective engagement programmes has been widely recognized in recent years (McKinley et al., 2020; Smith et al., 2017; Wilkins and Cooper, 2019). To strengthen the digital engagement of the various actors into inclusive and institutional networks, positive and proactive initiatives must exist, which will also help to overcome unpredictable situations bringing temporary closedowns of the in-field activities. The interactive tasks for these digital networks that ORP proposes include the following:

- Elaborate national and international thematic directories of engaged researchers.

- Create and/or curate national databases of engaged research projects and potential actors of partnerships.

- Develop a glossary of terms and a toolbox of engagement techniques to share. 
Table 2: Challenges and impacts originated by COVID-19 on the ORP network and potential strategies to mitigate them

\begin{tabular}{|c|c|}
\hline $\begin{array}{l}\text { Immediate and foreseen } \\
\text { challenges }\end{array}$ & Potential mitigation strategies \\
\hline In-field research & $\begin{array}{l}\text { - Work on the back end of data collection and cleaning } \\
\text { databases in preparation for in-field data retrieval restart } \\
\text { - Collection of data from people who are not ORP staff but } \\
\text { are still able to dive and snorkel }\end{array}$ \\
\hline Funding & $\begin{array}{l}\text { - Create campaigns and donation requests via social media } \\
\text { platforms }\end{array}$ \\
\hline Education in schools & $\begin{array}{l}\text { - Turtle Book Club (online) - sea turtle-centred book } \\
\text { recommendations, which can be used for a range of } \\
\text { activities in education centres with varied audiences } \\
\text { - Development of online e-turtle school dedicated to sea } \\
\text { turtle learning } \\
\text { - Creation of other online learning platforms aimed at } \\
\text { schoolchildren; video feeds to the Rescue Centre for one- } \\
\text { on-one learning }\end{array}$ \\
\hline Circular economy & $\begin{array}{l}\text { - Create stock (for example, dog leashes) while unable to } \\
\text { move products due to lockdown, in preparation for post- } \\
\text { lockdown times } \\
\text { - Creation of marketing materials ready for product launch } \\
\text { post-lockdown }\end{array}$ \\
\hline $\begin{array}{l}\text { Commercial partnership } \\
\text { cancellations }\end{array}$ & $\begin{array}{l}\text { - Search for, and engage with, additional partnerships } \\
\text { that are not linked to the tourism industry (for example, } \\
\text { sustainable fashion, sustainable living, and food and } \\
\text { beverages) }\end{array}$ \\
\hline Travel restrictions & - Remote work (at home) \\
\hline $\begin{array}{l}\text { Turtle patients - cannot } \\
\text { move turtles in the Maldives }\end{array}$ & - No mitigation possible \\
\hline No on-site vet & $\begin{array}{l}\text { - Provide online guidance to on-site biologist by veterinary } \\
\text { team abroad } \\
\text { - Reject medical emergencies; only caring for existing } \\
\text { patients }\end{array}$ \\
\hline $\begin{array}{l}\text { Temporary closure of our } \\
\text { second rescue centre }\end{array}$ & - Move turtle patients to the main Rehabilitation Centre \\
\hline $\begin{array}{l}\text { Visiting vets and volunteer } \\
\text { cancellations }\end{array}$ & $\begin{array}{l}\text { - Rescheduling of volunteer trips for later in the year and into } \\
2021\end{array}$ \\
\hline Maldivian internship & $\begin{array}{l}\text { - Extend internship period to help with daily tasks at the } \\
\text { Rescue Centre in the absence of the veterinarian }\end{array}$ \\
\hline Expansion delays & $\begin{array}{l}\text { - Plan Turtle Adoption Programme for when resorts reopen } \\
\text { - Find new partners not associated with the travel industry }\end{array}$ \\
\hline
\end{tabular}

- Promote and implement knowledge exchange opportunities, for example, programmes of events and conferences to be digitally hosted in various countries.

- Articulate the creation of standard impact statements to be embedded in future project proposals.

- Create protocols of best practices for engaged and collaborative research.

- Horizon scan and agree upon which are the urgent social needs and impactful research areas, and propose to the funding bodies to align their calls with these areas. 
- Develop ways to attract policymakers and industry stakeholders and to co-produce unifying policy documents to be shared among the networks and meta-networks of engaged researchers.

- Institutionalize and formalize administrative and scientific agreements for effective interactive and action future research.

As more people are turning to the internet and digital resources, ORP aims to keep up with these changes by providing online resources for sea turtle enthusiasts, academics and early career researchers. These resources include a combination of accredited and casual online courses that utilize ORP's knowledge of sea turtle science and conservation. The online tools could also be used to guide early career starters when making important decisions in their careers. Additionally, enriching higher education with accredited courses will provide a unique opportunity for sea turtle threats and marine pollution research areas to form part of a university degree.

\section{Concluding remarks}

The Olive Ridley Project provides an example of a strong and scientifically robust collaborative plan when coupled with enhanced community education and outreach. Based on the clear examples of research engagement and impact provided, the ORP programme can be seen as a model by which the challenges of engaging researchers and community actors are met, considering the local social and scientific frameworks. We suggest that similar programmes reflect upon ways to effectively combine scientific knowledge, education and action throughout all the stages of their inception, while bearing in mind that it is not only engaging different actors in the research that is beneficial; it is also crucial to provide evidence of the effects of their work on society. It is also essential that project sustainability is carefully planned to consider a variety of funding sources, which can be obtained by diversifying collaborations and partnerships with different sectors outside tourism, such as universities, the fashion industry and retail. Ultimately, to warrant the success of research engagement initiatives, institutional funding sources should provide supplementary budgets to extend the timelines of project programmes, implement durable partnerships, and make long-term societal benefit and societal participatory actions possible.

\section{Acknowledgements}

The authors would like to thank all past and present staff and volunteers of the Olive Ridley Project for their passion and dedication to sea turtle conservation over the years. We would also like to say a special thank you to Jannicke Hallum for her dedication and guidance in developing ORP's social and media presence. We are grateful to Dr Claire Petros for working with us to develop the first veterinarian-run sea turtle rehabilitation centre in the Maldives, and to Absar Khan for his passion and drive that kick-started the work of ORP in Pakistan. We extend our sincere gratitude to all commercial partners, resorts and spas and individual funders that have supported ORP over the years and made the research and conservation possible. Finally, we would like to give special acknowledgment to Mark Macdonald, Matthew Shoulders, Thorsten Albrecht, Laura and Shawn Holm, Robert Lawrence and Sue Filmer for their continued support.

\section{Conflicts of interest statement}

The authors declare no conflict of interest with this work. 


\section{Notes on the contributors}

Martin Stelfox is the founder and CEO of the Olive Ridley Project, and a researcher at the University of Derby, UK. Martin has extensive knowledge and experience working in the marine pollution sector, specifically ghost nets, and has been an amateur herpetologist since the age of 12 .

Mercedes Martin-Cereceda teaches microbiology and evolutionary biology at the Complutense University of Madrid, Spain. She researches the taxonomy and ecology of microbial eukaryotes, and has just finished a secondment year at the University of Derby, UK, as research impact officer for the UK Research Excellence Framework 2021 exercise.

Karim Vahed leads an MSc in conservation biology at the University of Derby, UK. His research focuses on insect behaviour and conservation. He is coordinator for the University of Derby's Earth Systems and Environmental Sciences submission (Unit 7) to the UK Government's Research Excellence Framework (REF 2021).

Jillian Hudgins is the Senior Project Scientist at the Olive Ridley Project. She has worked in the conservation field since 2009, and heads ORP's photo-ID project.

Stephanie Köhnk is an Olive Ridley Project researcher currently working from Germany. She has worked in sea turtle conservation in various parts of the world since 2007, and became part of the ORP team in 2017. Her main interests concern sea turtle population health and behaviour.

Usman Iqbal completed his BBA MBA in supply chain management from the Institute of Business and Management in Karachi, Pakistan. He has worked as an environmentalist in the solar energy sector, assisting with solar energy installations in the rural areas of Pakistan. Usman has also been involved with local fishermen in various development projects. Usman is the Project Manager for the Olive Ridley Project, Pakistan, and spearheads ORP's operations in Pakistan.

Ibrahim Shameel spent the last couple of years researching whale sharks with the Maldives Whale Shark Research Programme. He was a key member in carrying out the in-field research operation, as well as the community initiatives, such as the Maldives Whale Shark Festival. After spending a year in the UK to complete a foundation year in science, he is now completing his undergraduate degree in marine science at the Maldives National University. Shameel is a project coordinator for the Olive Ridley Project, based in the Maldives.

Joana M. Hancock has been the Olive Ridley Project's Project Manager in Kenya since 2018. Since 2002, she has worked in several sea turtle conservation projects in Central America and West Africa, where she is still actively collaborating with local conservation initiatives and ongoing research. Her main research interests are population connectivity and in-water studies, including foraging ecology and habitat use.

Michael Sweet is a lecturer and researcher at the University of Derby, UK. His main areas of research focus on the use of environmental DNA for the conservation of species and the detection of invasive organisms, the issues around plastics in the 
oceans, especially the problems caused by ghost gear and how climate change is affecting coral reefs around the world. He is an officer in the International Coral Reef Society, Research Chair for the British and Irish Association of Zoos and Aquariums, and founding Trustee for the Olive Ridley Project.

\section{References}

Brown, M. and Ward, P. (2019) 'Communities, universities and ethnicity: A conversation from Imagine: Connecting Communities Through Research'. Research for All, 3 (1), 91-104. https://doi.org/10.18546/RFA.03.1.08.

Burgess, M.G., Clemence, M., McDermott, G.R., Costello, C. and Gaines, S.D. (2018) 'Five rules for pragmatic blue growth'. Marine Policy, 87, 331-9. https://doi.org/10.1016/j.marpol.2016.12.005.

Campling, L. and Rosalie, M. (2006) 'Sustaining social development in a small island developing state? The case of Seychelles'. Sustainable Development, 14 (2), 115-25. https://doi.org/10.1002/ sd.298.

Chin, A., Baje, L., Donaldson, T., Gerhardt, K., Jabado, R.W., Kyne, P.M., Mana, R., Mescam, G., Mourier, J., Planes, S. and Wen, C. (2019) 'The scientist abroad: Maximising research impact and effectiveness when working as a visiting scientist'. Biological Conservation, 238, 1-7. https://doi.org/10.1016/j.biocon.2019.108231.

Cziesielski, M.J., Duarte, C.M., Aalismail, N., Al-Hafedh, Y., Anton, A., Baalkhuyur, F. et al. (2021) 'Investing in blue natural capital to secure a future for the Red Sea ecosystems'. Frontiers in Marine Sciences, 7, 603722. https://doi.org/10.3389/fmars.2020.603722.

Dunbar, S.G., Ito, H.E., Bahjri, K., Dehom, S. and Salinas. L. (2014) 'Recognition of juvenile Hawksbills Eretmochelys imbricatathrough face scale digitization and automated searching'. Endangered Species Research, 26, 137-46. https://doi.org/10.3354/esr00637.

European Commission (2018) Horizon 2020 in Full Swing - Three Years On: Key facts and figures 2014-2016. Accessed 24 July 2020. https://ec.europa.eu/programmes/horizon2020/sites/ horizon2020/files/h2020_threeyearson_a4_horizontal_2018_web.pdf.

European Commission (2020) 'Funding, tenders'. Accessed 24 July 2020. https://ec.europa.eu/ programmes/horizon 2020/en/h2020-section/societal-challenges.

Geissdoerfer, M., Savaget, P., Bocken, N.M.P. and Hultink, E.J. (2017) 'The circular economy A new sustainability paradigm?'. Journal of Cleaner Production, 143 (1), 757-68. https://doi.org/10.1016/j.jclepro.2016.12.048.

Hancock, J., Choma, J., Mainye, L., Stelfox, M. and Hudgins, J. (2020) 'Photo identification as a tool to study sea turtle populations in Kenyan marine protected areas'. Society for Conservation Biology. Accessed 30 June 2021. https://conbio.org/groups/sections/africa/act/photoidentification-as-a-tool-to-study-sea-turtle-populations-in-kenyan-ma.

Hind, E., Alexander, S.M., Green, S.J., Kritzer, J.P., Sweet, M.J., Johnson, A.E., Amargós, F.P., Smith, N.S. and Peterson, A.M. (2015) 'Fostering effective international collaboration for marine science in small island states'. Frontiers in Marine Sciences, 2, e86. https://doi.org/10.3389/ fmars.2015.00086.

Kelly, R., Fleming, A., Pecl, G.T., von Gönner, J. and Bonn, A. (2020) 'Citizen science and marine conservation: A global review'. Philosophical Transactions of the Royal Society B, 375, 20190461. https://doi.org/10.1098/rstb.2019.0461.

Krogh, A.H. and Nielsen, M.V. (2017) 'Succeeding with interactive research: How to manage research with and about society'. Research for All, 1 (2), 351-64. https://doi.org/10.18546/ RFA.01.2.11.

McKinley, E., Acott, T. and Yates, K.L. (2020) 'Marine social sciences: Looking towards a sustainable future'. Environmental Science and Policy, 108, 85-92. https://doi.org/10.1016/j. envsci.2020.03.015.

Nielsen, M.V. (2016) 'Organising Stakeholder Participation for Responsible Research and Innovation'. PhD thesis, Roskilde University.

ORP (Olive Ridley Project) (n.d.) Atlas of the Maldives: A comprehensive inventory of organisms affected by ghost nets in the Maldives. Accessed 30 June 2021. https://oliveridleyproject.org/ wp-content/uploads/2019/04/Atlas-of-the-Maldives-Entangled-organisms-affected-by-ghostnets-Maldives.pdf.

ORP (Olive Ridley Project) (2020) 'ORP's Women In Science'. ORP blog, 10 February. Accessed 30 June 2021. https://oliveridleyproject.org/blog/orps-women-in-science. 
Owen, R., Macnaghten, P. and Stilgoe, J. (2012) 'Responsible research and innovation: From science in society to science for society, with society'. Science and Public Policy, 39 (6), 751-60. https://doi.org/10.1093/scipol/scs093.

Pascual, U., Balvanera, P., Díaz, S., Pataki, G., Roth, E., Stenseke, M. et al. (2017) 'Valuing nature's contributions to people: The IPBES approach'. Current Opinion in Environmental Sustainability, 26/7, 7-16. https://doi.org/10.1016/j.cosust.2016.12.006.

Rasool, Z. (2017) 'Collaborative working practices: Imagining better research partnerships'. Research for All, 1 (2), 310-22. https://doi.org/10.18546/RFA.01.2.08.

Schofield, G., Katselidis, K.A., Dimopoulos, P. and Pantis, J.D. (2008) 'Investigating the viability of photo-identification as an objective tool to study endangered sea turtle populations'. Journal of Experimental Marine Biology and Ecology, 360 (2), 103-8. https://doi.org/10.1016/j. jembe.2008.04.005

Silver, J.J. and Campbell, L.M. (2018) 'Conservation, development and the blue frontier: The Republic of Seychelles' Debt Restructuring for Marine Conservation and Climate Adaptation Program'. International Social Science Journal, 68, 241-56. https://doi.org/10.1111/issj.12156.

Smith, N.S., Côté, I.M., Martinez-Estevez, L., Hind-Ozan, E.J., Quiros, A.L., Johnson, N., Green, S.J., Cornick, L., Shiffman, D., Malpica-Cruz, L., Gleason Besch, A. and Shiel-Rolle, N. (2017) 'Diversity and inclusion in conservation: A proposal for a Marine Diversity Network'. Frontiers in Marine Science, 4, 234. https://doi.org/10.3389/fmars.2017.00234.

Southby, K. (2017) 'Reflecting on (the challenge of) conducting participatory research as a researchdegree student'. Research for All, 1 (1), 128-42. https://doi.org/10.18546/RFA.01.1.10.

Stelfox, M.R. (2019) 'The Cryptic and Transboundary Nature of Ghost Gear in the Maldivian Archipelago'. PhD thesis, University of Derby.

Stelfox, M., Bulling, M. and Sweet, M. (2019) 'Untangling the origin of ghost gear within the Maldivian archipelago and its impact on olive ridley (Lepidochelys olivacea) populations'. Endangered Species Research, 40, 309-20. https://doi.org/10.3354/esr00990.

Stelfox, M., Gravon, D. and Dutton, K. (2020) The Adventures of Olive the Sea Turtle: From nest to sea. Fargo, ND: Theran Press.

Sweet, M., Stelfox, M. and Lamb, J. (2019) Plastics and Shallow Coral Reefs: Synthesis of the science for policy-makers. United Nations Environment Programme (UNEP) Policy Report. Accessed 30 May 2020. https://wedocs.unep.org/bitstream/handle/20.500.11822/27646/plastic_corals. pdf? sequence $=1$ \&isAllowed $=y$.

Sweet, M., Burian, A. and Bulling, M. (2021) 'Corals as canaries in the coalmine: Towards the incorporation of marine ecosystems into the "One Health" concept'. Journal of Invertebrate Pathology, 107538. https://doi.org/10.1016/j.jip.2021.107538.

UNDESA (United Nations Department of Economic and Social Affairs) (2017) 'Sustainable development knowledge platform: Small island developing states'. Accessed 17 January 2018. https://sustainabledevelopment.un.org/topics/sids.

UNESCO (United Nations Educational, Scientific and Cultural Organization) (2017) Cracking the Code: Girls' and women's education in science, technology, engineering and mathematics (STEM). Accessed 29 August 2020. https://unesdoc.unesco.org/ark:/48223/pf0000253479.

UNESCO (United Nations Educational, Scientific and Cultural Organization) (2018) Women in Science (Institute for Statistics Fact Sheet No. 51). Accessed 29 August 2020. http://uis. unesco. $\mathrm{org} / \mathrm{sites} /$ default/files/documents/fs51-women-in-science-2018-en.pdf.

United Nations (2020) 'Take action for the Sustainable Development Goals'. Accessed 24 July 2020. http://www.un.org/sustainabledevelopment/ sustainable-development-goals/.

Ward, S., Butler, D., Adams, R., O'Callaghan, S., Warren, N., Wickett, M., Swire, H., de Mora, S. and Uden, C. (2018) 'Developing university-society partnerships with a focus on climate change impact research using the "business assist" model'. Research for All, 2 (1), 163-74. https://doi.org/10.18546/RFA.02.1.14.

Wilkins, T. and Cooper, I. (2019) 'Lessons from coordinating a knowledge-exchange network for connecting research, policy and practice'. Research for All, 3 (2), 204-17. https://doi.org/10.18546/RFA.03.2.07. 